\title{
Perfil de bebês praticantes de natação
}

\author{
Profile of swimming babies
}

Resumo Atividades aquáticas podem estimular a desenvoltura de crianças, respeitando seu progresso natural e ao mesmo tempo ensinar de forma leve, lúdica e prazerosa, novas habilidades e descobertas para o corpo. O presente trabalho teve por objetivo analisar o perfil de bebês praticantes de natação de uma academia privada em Piumhi/MG, abordando a visão de responsáveis e/ou acompanhantes sobre aspectos vinculados aos benefícios da estimulação aquática encontrados na literatura. Foi realizada pesquisa de campo com caráter quantitativo, transversal e observacional, com a utilização de questionário, elaborado após pesquisa bibliográfica acerca dos benefícios da estimulação aquática, com perguntas diretas ("SIM" e "NÃO"). A amostragem consta de 11 participantes correspondentes a seis bebês do sexo feminino e cinco do sexo masculino, na faixa etária de 6 a 18 meses de idade. Os dados coletados foram organizados e analisados observando a resposta positiva ("SIM") ou negativa ("NÃO) respondidos em vários aspectos observacionais na visão dos responsáveis como: melhora no desenvolvimento motor, reflexos, equilíbrio, chorar para ir para a aula ou sair dela, adaptação ao meio líquido, segurança, entre outros, após iniciarem a prática da estimulação aquática. Além disso, o questionário requeria preenchimento de informações pessoais da criança como nome, sexo, tempo de prática, entre outros. Para tratamento dos dados obtidos, foram utilizadas tabelas de distribuição de frequências, gráfico de setores e dados de percentual (válido e acumulativo). Foi considerado o nível de significância de $5 \%$ e usado o software estatístico (SPSS) versão 23.0. Conclui-se que os benefícios da estimulação aquática encontrados na literatura, podem ser evidenciados nos bebês pesquisados. Não foram constatados malefícios a respeito da estimulação aquática nem na literatura muito menos na pesquisa atual. Além disso, fica retratado de forma indireta e observacional que o desenvolvimento normal e satisfatório exibido pelos bebês na visão dos responsáveis pode ser atribuído também à estimulação aquática já que são esses responsáveis que possuem propriedade para apontar aspectos positivos quanto ao desenvolvimento e a satisfação dos bebês após a iniciação da prática aquática.

Palavras-chave: Criança. Desenvolvimento. Natação.

Jéssica de Fátima Alves ${ }^{1}$ Paulo Márcio Montserrat II Gleuber Henrique Marques-OLIVEIRA ${ }^{\text {II }}$

'Graduação em Educação Física Bacharelado. Centro Universitário de Formiga - UNIFOR/MG

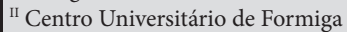
(UNIFOR/MG). Formiga/MG Brasil
ABSTRACT Water activities can stimulate children's resourcefulness, respecting their natural progress and at the same time teaching in a light, playful and pleasant way, new skills and discoveries for the body. The present study aimed to analyze the profile of babies who practice swimming in a private gym in Piumhi/MG, addressing the view of guardians and/or companions on aspects related to the benefits of aquatic stimulation found in the literature. Field research with quantitative, transversal 
and observational character was carried out, using a questionnaire, elaborated after bibliographical research on the benefits of aquatic stimulation, with direct questions ("YES" and "NO"). The sample consists of 11 participants corresponding to six female babies and five male babies, in the age group from 6 to 18 months of age. The collected data were organized and analyzed observing the positive ("YES") or negative ("NO") responses answered in several observational aspects in the view of those responsible, such as: improvement in motor development, reflexes, balance, if they cry when go to class or leave it, adaptation to the liquid environment, safety, among others, after starting the practice of aquatic stimulation. In addition, the questionnaire required filling in the child's personal information such as name, sex, practice time, among others. To treat the obtained data, frequency distribution tables, sector graph and percentage data (valid and cumulative) were used. The significance level of $5 \%$ was used and the statistical software (SPSS) version 23.0 was used. It is concluded that the benefits of aquatic stimulation found in the literature, can be evidenced in the researched babies. No harm has been found on aquatic stimulation or in the literature, much less in current research. In addition, it is portrayed in an indirect and observational way that the normal and satisfactory development presented by the babies in the view of the guardians can also be attributed to aquatic stimulation since these are the guardians who have the property to point out positive aspects regarding the development and satisfaction of the babies after the initiation of aquatic practice.

Keywords: Child. Development. Swimming.

\section{INTRODUÇÃo}

O desenvolvimento e o progresso do ser humano ocorrem de forma conjunta envolvendo aspectos cognitivos, afetivos, sociais e motores, que vão se modificando ao passar do tempo. A quantidade e a qualidade das experiências que se vive têm grande influência na mudança e no desenvolvimento da criança e do adolescente até sua idade adulta. ${ }^{1,2}$

A estimulação é um processo natural em que o bebê vivencia todos os dias uma relação com o ambiente em que se encontra e as pessoas que se tem contato, permitindo que conheça a si mesmo, relacionando sua personalidade ao seu corpo. Essa estimulação começa nos primeiros meses de vida devido às repetições de suas ações, permitindo ao bebê um maior controle emocional e uma melhor aprendizagem como um todo. ${ }^{3}$

Um dos tipos de estimulação é quanto ao sistema sensorial, em que o bebê baseia seu aprendizado em seus próprios sentidos. Seguindo essa premissa, o exercício aquático é um dos estímulos mais recomendados para bebês. Atividades na piscina podem apresentar grande potencial de utilização, visto que podem proporcionar ao bebê adaptação ao meio aquático desde cedo, favorecendo a relação da criança com a água por toda a sua vida. ${ }^{4,1}$

Além disso, pode proporcionar grande momento de prazer e diversão, melhorar o desenvolvimento motor e o sistema imunológico, fortalecer a musculatura, estimular o apetite, proporcionar um sono mais tranquilo e incentivar a interação do bebê com 
os pais e educadores, aumentando as experiências sensoriais e motoras da criança, facilitando questões de cunho verbal, gestual e afetivo. ${ }^{5,6,3}$

Quando não é realizado qualquer estímulo ou contato com o meio aquático, bebês de até 1 ano de idade podem sofrer perda gradual do "costume" ao meio líquido, adquirido desde o útero materno, podendo acarretar em perda de reflexos. Esse fato, pode ser evitado por intermédio de atividades na piscina que favorecem até mesmo a segurança da criança. O estímulo aquático evita acidentes quando a criança cai em algum local com água pois, nas imersões, um tipo de estímulo através do mergulho, a criança de forma natural provoca o bloqueio da glote, fazendo que não ocorra seu afogamento imediato. $^{7}$

O contato dos bebês com o meio aquático é recomendado a partir dos 6 meses de idade, quando o bebê já tomou a maioria das vacinas necessárias, assim, está em um grande momento de desenvolvimento e pronto para uma leve atividade física. ${ }^{8,9}$

Mas essas informações encontradas na literatura podem ser observadas em qualquer tipo de amostragem? Assim, essa pesquisa tem como objetivo analisar se as informações obtidas na literatura sobre os benefícios da estimulação aquática podem ser evidenciadas em bebês praticantes de uma academia privada do município de Piumhi/MG. A pesquisa aborda a visão dos responsáveis e/ou acompanhantes dos bebês sobre o tema em determinado ponto no tempo, para analisar o perfil dos bebês pesquisados, fazendo conexão aos resultados obtidos em outras literaturas.

\section{Metodologia}

Este estudo se apresenta como pesquisa de campo com caráter quantitativo, transversal e observacional, o qual foi aprovado pelo comitê de ética em pesquisa em seres humanos com o parecer número 2.508.630.

Foi realizada entrevista com os responsáveis e/ou acompanhantes de 11 alunos (seis do sexo feminino e cinco do sexo masculino), na faixa etária de 6 a 18 meses de idade, do turno matutino de uma academia aquática privada de Piumhi/MG com a utilização de questionário desenvolvido pela equipe de pesquisa.

O questionário foi produzido observando (após feita pesquisa bibliográfica sobre o tema) os benefícios citados na literatura a respeito da estimulação aquática em bebês. Antes da realização da entrevista, foi entregue aos participantes o termo de consentimento livre e esclarecido, o qual informa acerca da realização da pesquisa, os objetivos do estudo e os cuidados éticos tomados como, por exemplo, a confidencialidade das informações bem como a não identificação dos entrevistados. Os termos foram assinados e, só após, foram realizadas as entrevistas para a coleta de dados.

Para a execução da pesquisa foi escolhido determinado dia e horário de aula de natação do bebê com consenso entre pesquisador, professor e proprietário do local do estudo. O pesquisador levou várias cópias do questionário impressas e esteve presente todo o tempo, enquanto os participantes respondiam às perguntas esclarecendo eventuais dúvidas sobre algum item da pesquisa. O questionário continha perguntas em forma de tabela. Foi entregue no início da aula 
e recolhido quando o participante terminou, não sendo estipulado tempo definido para que cada responsável e/ou acompanhante respondesse com calma, exibindo respostas diretas entre "sim" e "não", além de: nome da criança, sexo, tempo de prática de natação, faixa etária, nome do responsável e seu parentesco com a criança.

Para organização e tratamento dos dados obtidos, inicialmente foram utilizadas tabelas de distribuição de frequências para descrever os resultados, bem como, gráfico de setores e dados de percentual (válido e acumulativo). Em todas as análises foi considerado o nível de significância de 5\% e utilizado o software estatístico Statistical Package Social Sciences (SPSS) versão 23.0 e o Microsoft Office Excel.

\section{Resultados}

Foram produzidos quadros demonstrativos da relação de cada quesito para os alunos. Inicialmente, quanto à idade, um aluno de 10 meses, um aluno de 11, um aluno de 12 , um aluno de 14 , um aluno de 15 , dois alunos de 16, um aluno de 17 , e, por fim, três alunos de 18 meses, totalizando os 11 alunos participantes da pesquisa (Tabela 1).

Tabela 1 - Relação de idade dos alunos.

\begin{tabular}{c|c|c|c}
\hline $\begin{array}{c}\text { Idade } \\
\text { (Meses) }\end{array}$ & $\begin{array}{c}\text { Frequência } \\
\text { (Aluno) }\end{array}$ & Percentual & $\begin{array}{c}\text { Percentual } \\
\text { Acumulativo }\end{array}$ \\
\hline 10 & 1 & 9,1 & 9,1 \\
\hline 11 & 1 & 9,1 & 18,2 \\
\hline 12 & 1 & 9,1 & 27,3 \\
\hline 14 & 1 & 9,1 & 36,4 \\
\hline 15 & 1 & 9,1 & 45,5 \\
\hline 16 & 2 & 18,2 & 63,7 \\
\hline 17 & 1 & 9,1 & 72,8 \\
\hline 18 & 3 & 27,2 & 100,0 \\
\hline Total & $\mathbf{1 1}$ & $\mathbf{1 0 0 , 0}$ & \\
\hline
\end{tabular}

Quanto ao sexo, seis alunos do sexo feminino, com percentual válido $54,4 \%$ e cinco masculinos, com percentual válido de $45,5 \%$, sendo o percentual acumulativo de $54,5 \%$ e 100 , respectivamente.

Quanto ao tempo de prática, 2 alunos praticam a 3 meses, 4 alunos a 4 meses, 1 aluno a 5 meses, 1 aluno a 6,1 aluno a 7, 1 aluno a 8, e finalizando 1 aluno a 9 meses, totalizando os 11 alunos (Tabela 2).

Quanto à relação de acompanhamento para as aulas, seis alunos são acompanhados pela própria mãe, um aluno pelo pai, dois alunos pela babá, um aluno pela prima e um aluno pela tia (Tabela 3). 
Tabela 2 - Relação de tempo de prática do meio aquático.

\begin{tabular}{c|c|c|c}
\hline $\begin{array}{c}\text { Tempo } \\
\text { (Meses) }\end{array}$ & $\begin{array}{c}\text { Frequência } \\
\text { (Alunos) }\end{array}$ & $\begin{array}{c}\text { Percentual } \\
\text { Válido }\end{array}$ & $\begin{array}{c}\text { Percentual } \\
\text { Acumulativo }\end{array}$ \\
\hline 3 & 2 & 18,2 & 18,2 \\
\hline 4 & 4 & 36,3 & 54,5 \\
\hline 5 & 1 & 9,1 & 63,6 \\
\hline 6 & 1 & 9,1 & 72,7 \\
\hline 7 & 1 & 9,1 & 81,8 \\
\hline 8 & 1 & 9,1 & 90,9 \\
\hline 9 & 1 & 9,1 & 100,0 \\
\hline Total & $\mathbf{1 1}$ & $\mathbf{1 0 0 , 0}$ & \\
\hline
\end{tabular}

Tabela 3 - Relação sobre os acompanhantes dos alunos.

\begin{tabular}{c|c|c|c}
\hline Acompanhantes & $\begin{array}{c}\text { Frequência } \\
\text { (Alunos) }\end{array}$ & $\begin{array}{c}\text { Percentual } \\
\text { Válido }\end{array}$ & $\begin{array}{c}\text { Percentual } \\
\text { Acumulativo }\end{array}$ \\
\hline MÃE & 6 & 54,5 & 54,5 \\
\hline PAI & 1 & 9,1 & 63,6 \\
\hline BABÁ & 2 & 18,2 & 81,8 \\
\hline PRIMA & 1 & 9,1 & 90,9 \\
\hline TIA & 1 & 9,1 & 100,0 \\
\hline Total & $\mathbf{1 1}$ & $\mathbf{1 0 0 , 0}$ & \\
\hline
\end{tabular}

Quanto aos alunos que choram indo para a aula, seis responsáveis responderam que sim, com percentual válido de $54,4 \%$ e cinco que não choram, com percentual válido de $45,5 \%$, sendo o percentual acumulativo de $54,5 \%$ e 100 , respectivamente.

Quanto à adaptação inicial no meio líquido, oito alunos se adaptaram, com percentual válido de $72,2 \%$ e três não, com $27,3 \%$ de percentual válido, sendo o percentual acumulativo de $72,7 \%$ e 100 , respectivamente.

Quanto ao gosto pela piscina (meio líquido), todos os responsáveis afirmaram que os bebês gostam do meio aquático, sendo que os percentuais ficaram todos em 100\%. A mesma resposta positiva (SIM) e, unânime, foi observada quanto às perguntas sobre o bom relacionamento do bebê com o professor, a respeito de se divertir nas aulas de natação, sobre dormir melhor à noite e acerca da melhora dos alunos no desenvolvimento motor, desenvolvimento da força, equilíbrio, reflexos, segurança e outros quesitos em geral depois da prática da natação.

Quanto ao afogamento nas aulas, de acordo com os responsáveis e/ou acompanhantes nenhum aluno, felizmente, passou 
por esse incidente sendo, resposta unânime, quanto a esse aspecto e quanto às lesões, ou seja, nenhum participante da pesquisa se afogou ou apresentou lesões devido à estimulação aquática.

Alguns aspectos que podem ser interpretados de maneira positiva quanto aos benefícios da estimulação aquática são as respostas unânimes quanto aos questionamentos sobre a criança ficar nervosa nas aulas e querer ir embora, todos responderam que "não", também, quanto a brincar com outras crianças, se sentir bem em outras piscinas e se sentir à vontade, todos responderam que "sim".

\section{Discussão}

Muitos foram os estudos encontrados na literatura sobre o tema. Algumas pesquisas apresentam metodologia, de certa forma, semelhante e resultados significativos acerca do desenvolvimento da criança quando obteve estimulação aquática precoce ou estudaram o mesmo benefício dentro do tema proposto.

Pereira ${ }^{10}$ estudou a influência no desenvolvimento motor de bebês praticantes e não praticantes de atividades aquáticas, levando em conta, gênero, faixa etária e tempo de prática, totalizando 80 bebês pesquisados de 01 a 18 meses. Segundo Pereira, ${ }^{10} 100 \%$ dos bebês praticantes de atividade aquática apresentam desenvolvimento motor normal, enquanto que, no grupo dos bebês não praticantes, alguns foram classificados com atraso (meninos $14,3 \%$ e meninas $10,5 \%$ ), outros suspeita de atraso (meninos 28,6\% e meninas $15,8 \%$ ), e também aqueles com desenvolvimento normal (meninos 57,1\% e meninas $73,7 \%$ ). Os resultados obtidos nesta pesquisa podem ser evidenciados também no estudo em questão que utilizou um questionário para analisar se os bebês pesquisados, também até 18 meses de idade, estão se desenvolvendo de maneira normal quanto à parte motora pela visão de responsáveis e/ou acompanhantes. Apesar de uma única coleta de dados e sem a utilização de grupo controle como já citado na literatura, o estudo atual mostra dados semelhantes, exibindo $100 \%$ das respostas como "sim"; quando os pesquisados foram perguntados se evidenciado por eles melhoria (desenvolvimento normal) na coordenação motora, equilíbrio e força. Além disso, os dois trabalhos (atual e da literatura) confirmam os dados de forma independente ao tempo de prática (no trabalho atual de 3 a 9 meses de prática) já que os resultados foram positivamente satisfatórios em todos os praticantes nos dois estudos. Os pesquisados acreditam que os bebês apresentam desenvolvimento geral normal de acordo com a idade, mostrando que a estimulação aquática pode favorecer esse quesito na vida do bebê.

Ainda sobre o quesito desenvolvimento motor infantil por meio da natação, pode-se citar o estudo Lamp e Silva ${ }^{11}$ que analisou o desenvolvimento motor de crianças praticantes de natação em relação a crianças não praticantes dessa modalidade, de ambos os gêneros, totalizando 35 crianças de ambos os sexos. A metodologia adotada consistiu em provas de habilidade com classificação do quociente motor relacionado ao equilíbrio, organização temporal e espacial e motricidade fina e global. Os resultados demonstraram que o grupo de crianças praticantes de natação, em sua totalidade, exibiram resultado superior ao de crianças não pratican- 
tes. Em confronto com o artigo atual, que considerou como dado de interpretação as opiniões dos responsáveis, pode-se inferir que a visão deles, a respeito dos benefícios da estimulação aquática nas crianças, se encontra em outros estudos com apresentação de dados científicos.

O estudo de Gomes ${ }^{12}$ trouxe uma metodologia semelhante à aplicada neste artigo, também com a utilização de questionários contando diversas perguntas sobre a vida dos bebês e seu convívio com o meio aquático. Foram analisados nove questionários com bebês de até 3 anos de idade. Nos dois estudos, pode-se inferir que os responsáveis acreditam nos benefícios que a estimulação aquática oferece ao bebê e confirmam o gosto dos mesmos pelo meio aquático, além disso, ambos os estudos consideram os bebês pesquisados com desenvolvimento normal de acordo com a idade de uma forma geral, mesmo pesquisando crianças de idade mais avançada.

Outro estudo que faz uso da metodologia de questionários, a mesma adotada pelo artigo em questão, é o de Martins et al. ${ }^{13}$ Os autores analisaram a importância que os pais atribuíam à prática de natação em relação ao desenvolvimento do bebê totalizando 66 pesquisados. Na pesquisa de Martins et al., ${ }^{13}$ um quesito de maior destaque como resultado foi quanto ao questionamento sobre o motivo de colocarem as crianças na estimulação aquática. As duas maiores porcentagens de resposta atribuíram o motivo à saúde e ao desenvolvimento e, em seguida, lazer e relação social. Esses temas também foram pesquisados pelo artigo atual em questionamentos como: A criança, na sua opinião, melhorou seu desenvolvimen- to, coordenação motora, equilíbrio e força? Pode-se interpretar que ninguém melhor do que os pais ou responsáveis para observar, de maneira diária, o desenvolvimento e evolução da criança e na visão deles os quesitos saúde, desenvolvimento, lazer e relação social são benefícios também associados à estimulação aquática. $O$ trabalho atual apresenta, de forma unânime, opiniões que fortalecem os resultados encontrados por Martins et al. ${ }^{13}$

Outra pesquisa relacionada ao tema deste trabalho foi feita por Mataruna e Salles. ${ }^{14}$ A pesquisa também utilizou a metodologia de questionário para obtenção de dados. A amostragem consistiu de professores de natação e responsáveis pelos bebês, ambos responderam questionários diferentes: o primeiro com o objetivo de verificar aspectos educacionais e o segundo sobre as expectativas e a relação da família com as atividades aquáticas. Em seus resultados, acerca da visão educacional, adaptação ao meio líquido, afetividade e o desenvolvimento psicomotor, foram os três aspectos mais pontuados a respeito dos efeitos da natação infantil. Já sobre a visão das famílias, desenvolvimento psicomotor e autoconfiança foram os quesitos prioritários. O mesmo ocorre na pesquisa deste trabalho, em que os responsáveis deixam claro esses mesmos quesitos positivos, na observação deles, com a prática da atividade, não só em relação ao desenvolvimento que se acelera, mas também a outros fatores benéficos que podem, indiretamente, melhorar a eficiência e a qualidade de vida da criança como um todo, com autoconhecimento.

O estudo de Pontarolli ${ }^{15}$ destaca os níveis de adesão, motivos de prática e desis- 
tência da estimulação aquática para bebês. A amostragem foi de 85 crianças de 0 a 4 anos de idade, como amostragem total, durante um ano. Foram entrevistados pais de 53 crianças desistentes, em questões como: motivo de entrada, acompanhante, avaliação dos recursos físicos e humanos, incidência de doenças e motivo da saída. Entre toda a amostra, o índice de adesão às aulas foi de $29,42 \%$ no período de um ano, enquanto $70,58 \%$ desistiram. Entre todos os resultados, os motivos pelos quais escolhem a natação para os bebês são os que mais se destacam, sendo que a maior porcentagem $(79,25 \%)$ é o desejo dos próprios pais e, posteriormente, indicação médica e segurança. A respeito do quesito acompanhante, também mencionado na pesquisa deste trabalho, percebemos que, enquanto nos resultados de Pontarolli ${ }^{15}$ a mãe é presente em todos os segmentos sobre o acompanhamento com a criança, no artigo atual há outras pessoas, além da mãe, que acompanham a criança sendo que, de 11 alunos, 18,18\% são acompanhados pela babá, 9,09\% pela prima, 54,54\% pela mãe, 9,09\% pela tia e também 9,09\% pelo pai. Além disso, pode-se evidenciar outro quesito estudado pelo artigo atual que se destaca nesta pesquisa: a segurança. Esse aspecto é exibido como o segundo quesito de maior resultado na pesquisa de Pontarolli, ${ }^{15}$ enquanto no artigo atual a totalidade dos responsáveis respondeu que o bebê se sente seguro nas aulas, não se afogou nem teve qualquer lesão. Isso demonstra que o fator segurança abrange tanto a segurança individual da criança em praticar a atividade quanto evitar possíveis acidentes de afogamento e é considerado benefício alcançado pela estimulação aquática na visão dos responsáveis.

Carvalho e Coelho ${ }^{16}$ realizaram outro estudo, nessa mesma área, buscando informações com os pais de crianças que praticam natação e os motivos que os levaram a matriculá-las. O instrumento de coleta dos dados foi desenvolvido por meio de questionários, que foram direcionados a 43 pais de alunos de natação de uma academia particular. A amostra constitui-se de ambos os sexos, com idade entre 3 a 11 anos e que participam ativamente da atividade há, no mínimo, 3 meses. Dessa forma, os autores concluíram que os pais nem sempre matriculam seus filhos nas aulas de natação com o objetivo de formarem um hábito que lhes renderá boa saúde física e mental, qualidade de vida e aprendizados significativos, pois não sabem que os benefícios da natação vão muito além de aprender a nadar ou simplesmente se adaptar ao meio líquido. Constata-se, porém, que após algum tempo de prática, mesmo não tendo todos os seus objetivos iniciais contemplados, os pais percebem outros benefícios alcançados, como desenvolvimento motor e sensorial se mostrando satisfeitos com os resultados apresentados por seus filhos até o momento e confirmando o potencial da natação como ferramenta de estímulo.

Quanto ao trabalho atual, no questionário não constam perguntas aos pais sobre os motivos de matricular os filhos na natação, e as idades das crianças também modificam sendo um pouco mais novas, o que difere do estudo citado. Porém, os benefícios da natação ficam de forma indireta evidenciados, em ambos, em que os próprios responsáveis pelos bebês praticantes 
afirmam a variedade de quesitos que melhoram na vida do bebê, já que todos responderam os questionários de forma positiva para essa interpretação de dados.

Também, analisando a visão dos responsáveis, foi encontrado o estudo de Espada $^{17}$ et al., os quais aferiram o perfil dos pais e a percepção desses às aulas de natação para bebês. Foram pesquisados 45 pais em três piscinas do Distrito de Setúbal e a metodologia adotada também foi de questionários. A totalidade dos pais considerou relevante a emissão de feedback por parte dos professores de natação para bebês nas aulas e o conhecimento das metodologias aplicadas. É fundamental caracterizar os responsáveis pelo envolvimento de bebês em aulas de natação e compreender e analisar as suas observações sobre a natação para bebês no sentido de adaptar as ideias em amplo crescimento. $\mathrm{O}$ estudo atual também considera a visão dos responsáveis de fundamental importância, já que são eles que podem nos dizer as melhorias e benefícios observados na criança quanto ao desenvolvimento geral após a matrícula das aulas. E, por mais que esses responsáveis matriculem os bebês na procura de benefícios para a criança, apontar as melhorias é importantíssimo e fazê-los refletir.

Apesar de diferenças existentes sobre os trabalhos, a maioria dos estudos fortalecidos com a pesquisa atual defende a utilização da atividade aquática como ferramenta benéfica para a estimulação dos bebês. Os estudos não relatam qualquer tipo de ma- lefício e inferem que, os bebês, podem se desenvolver bem a partir do momento que começam a praticar a atividade com saúde e qualidade de vida.

\section{CONSIDERAÇõeS FINAIS}

Conclui-se que cada criança tem seu desenvolvimento natural e que este deve ser respeitado. Mas, os benefícios da estimulação aquática, encontrados na literatura, podem ser evidenciados nos bebês pesquisados, na opinião dos responsáveis. Não foram constatados malefícios sobre a estimulação aquática nem na literatura muito menos na pesquisa atual. Além disso, fica retratado de forma indireta e observacional que o desenvolvimento normal e satisfatório apresentado pelos bebês na visão dos responsáveis pode ser atribuído também pela estimulação aquática já que são os responsáveis que possuem propriedade para apontar aspectos positivos ou negativos quanto ao desenvolvimento e a satisfação do bebê, após a iniciação da prática aquática.

Os relatos positivos e motivadores encontrados em literaturas sobre o estímulo aquático em bebês foram confirmados, de forma geral, neste estudo com a análise das respostas dos responsáveis. Corroborando que, a estimulação aquática em bebês pode ser utilizada como aliada para melhorar o desenvolvimento da criança de forma geral. E, assim, proporcionar bem-estar e alegria ao nadar pelo decorrer da vida com mais qualidade de vida e saúde. 


\section{REFERÊNCIAS}

1. SILVA, J. O.; MARTINS, J. C., DE SOUZA MORAIS, R. L., \& GOMES, W. F. Influência da estimulação aquática no desenvolvimento de crianças de 0 a 18 meses: um estudo piloto. Fisioterapia e Pesquisa, v. 16, n. 4, p. 335-340, 2009.

2. PAIVA, M. M. S. A Afetividade e o Processo Ensino-Aprendizagem, 2019.

3. MACHADO, B. R. Natação e o desenvolvimento em crianças de zero a dois anos de idade. São Paulo: Fontoura, 2016.

4. NUNES, A. S. D.; CHAHINI, T. H. C. Percepções de profissionais da educação infantil em relação à estimulação precoce em crianças com deficiência e de risco ambiental. Revista Interdisciplinar em Cultura e Sociedade, p. 83-102, 2017.

5. ANDRADE, F. A.; SILVA, A. E. B. Perfil motivacional de pais que inserem seus filhos a prática da natação infantil, 2016, 85s. Trabalho de conclusão de curso (Graduação de Bacharelado em Educação Física) - Universidade de São Paulo, São Paulo, SP.

6. MORAES, R. B. Atividades aquáticas para bebês: análise da estrutura dos programas e das escolas/academias de natação, 2011.

7. ZUQUIM, E. V. S. Motivação dos pais para colocar seus filhos na natação na primeira infância, 2016, 63s. Trabalho de conclusão de curso (Graduação em Licenciatura de Educação Física) - Universidade Federal de Viçosa, Minas Gerais.

8. BELTRAME, W. P. Fatores motivacionais que influenciam a prática de atividades físicas, 2015, 81s. Trabalho de conclusão de curso (Graduação de Educação Física Plena) - Universidade de Rio Verde, Goiás.

9. FIGUEIREDO, P. A. P de. Natação para bebês, infantil e iniciação: uma estimulação para a vida. São Paulo: Phorte Editora LTDA, 2011.

10. PEREIRA, K. R. G. Atividades aquáticas para bebês: influência no desenvolvimento motor, 2009, 73 p. Trabalho de conclusão de curso (Graduação de Licenciatura em Educação Física) Universidade Federal do Rio Grande do Sul, Porto Alegre, 2009.

11. LAMP, C. R.; SILVA, A. S. Análise do desenvolvimento motor de crianças de $\mathbf{3}$ a 5 anos praticantes e não praticantes de natação do município de Cacoal/RO. Cacoal, v. 4, n. 2, jul./dez. 2015.

12. GOMES, R. C. A. Natação para bebês: motivos para a realização desta prática corporal segundo os pais e/ou responsáveis, 2016, 67 p. Trabalho de conclusão de curso (Graduação de Licenciatura em Educação Física) - Universidade Federal de Goiás, Goiânia, 2016.

13. MARTINS, M., MOREIRA, A., SILVA, A., AIDAR, F., MIRANDA NETO, J. T., \& VIEIRA, M. Caracterização do desenvolvimento de crianças (6-36 meses) participantes em aulas de adaptação ao meio aquático para bebês. Motricidade, v. 2, n. 2, 2006.

14. MATARUNA, L.; SALLES, P. G. Natação para bebês: retrato da realidade em Nova Iguaçu/RJ, 2011, 12 p. Trabalho de pós-graduação. Centro Universitário de UNIABEU, Rio de Janeiro, 2011.

15. PONTAROLLI, J. L. Níveis de adesão nos praticantes de natação para bebês, 29 p. Trabalho de conclusão de curso (Graduação de Bacharel em Educação Física) - Universidade Federal do Paraná, Curitiba, 2006.

16. CARVAlHO, A. B. P. C.; COELHO, D. C. M. Natação para crianças: o que motiva os pais a escolherem esta modalidade esportiva para seus filhos, 2011, 6 p. Tese mestrado - Universidade Castelo Branco, Rio de Janeiro, 2011.

17. ESPADA, M. Caracterização dos pais e percepção dos mesmos sobre aulas de natação para bebês. Revista UIIPS, v. 7, n. 2, p. 157-167, 2019. 


\section{DADOS DOS AUTORES}

\section{Jéssica de Fátima Alves}

Educação Física Bacharelado. Centro Universitário de Formiga. Formiga/MG - Brasil. jes.alves@ outlook.com.br

\section{Paulo Márcio Montserrat}

Mestrado Profissional em Desenvolvimento Regional pela Universidade Estatual de Minas Gerais (UEMG). Professor no Centro Universitário de Formiga. Formiga/MG - Brasil. paulomarcio@uniformg.edu.br

\section{Gleuber Henrique Marques-Oliveira}

Doutor em Bioquímica e Biologia Molecular pela Universidade Federal de São João Del Rei (UFSJ). Professor no Centro Universitário de Formiga. Formiga/MG - Brasil.gleuberh@gmail.com

Submetido em: 29-11-2018

Aceito em: 22-6-2020 